\title{
The effect of exercise on aromatase inhibitor-induced musculoskeletal symptoms in breast cancer survivors :a systematic review and meta-analysis
}

\author{
Geling $\mathrm{Lu}^{1} \cdot$ Jin Zheng $^{1}$ (D) Lei Zhang $^{2}$ \\ Received: 14 August 2019 / Accepted: 7 November 2019 / Published online: 18 December 2019 \\ (C) The Author(s) 2020
}

\begin{abstract}
Background Evidence is mixed regarding the effect of exercise programs on improving musculoskeletal symptoms and quality of life. Previous meta-analyses have not focused specifically on the musculoskeletal symptoms. Therefore, this meta-analysis aimed to evaluate the effect of exercise on these outcomes in breast cancer survivors taking aromatase inhibitors.

Methods PubMed, CINAHL, EMBASE, Web of Science, Wan Fang, CNKI, VIP, and CBM were searched for randomized control trials or quasi-experimental studies from the establishment of the database to May 2019. Studies comparing exercise programs with usual care among breast cancer survivors taking aromatase inhibitors were included. The primary outcome was the degree of musculoskeletal symptoms, as assessed by scores of pain, stiffness, and grip strength. The secondary outcome was the total quality of life score.

Results A total of 9 studies involving 743 participants were included. Exercise programs were more effective than usual care in improving musculoskeletal symptoms among breast cancer patients taking AIs. The subgroup scores of pain (SMD = $-0.46,95 \%$ $\mathrm{CI}-0.79$ to $-0.13, \mathrm{P}=0.006)$, stiffness $(\mathrm{SMD}=-0.40,95 \% \mathrm{CI}-0.71$ to $-0.08, \mathrm{P}=0.01)$, and grip strength $(\mathrm{SMD}=0.43,95 \% \mathrm{CI}$ 0.16 to $0.71, \mathrm{P}=0.002)$ benefited from exercise interventions. Similar effects were found for the quality of life scores $(\mathrm{SMD}=$ $2.24,95 \%$ CI 0.28 to $4.21, \mathrm{P}=0.03$ ).

Conclusions Results indicate that exercise relieves musculoskeletal symptoms and improves quality of life, which can be used to motivate patients to exercise actively under professional guidance. Due to a small sample size, further research is required to ensure the effectiveness of exercise on musculoskeletal symptoms and quality of life.
\end{abstract}

Keywords Breast cancer $\cdot$ Exercise $\cdot$ Aromatase inhibitor $\cdot$ Musculoskeletal symptoms $\cdot$ Meta-analysis

\section{Abbreviations}

AIs aromatase inhibitors

AIMSS aromatase inhibitor-associated musculoskeletal symptoms

QOL quality of life

Jin Zheng

9596909@qq.com

1 Department of Urology, The First Hospital of China Medical University, Liaoning, China

2 Department of Breast, The First Hospital of China Medical University, Liaoning, China

\section{Introduction}

Breast cancer is the most prevalent cancer in women worldwide [1]. Approximately $75 \%$ of breast cancer survivors are diagnosed with hormone-receptor-positive breast cancer [2]. As a part of standard adjuvant therapy for postmenopausal women diagnosed with hormone-receptor-positive breast cancer [3], aromatase inhibitors (AIs) have improved disease-free survival by $40 \%$; however, they also cause aromatase inhibitor-associated musculoskeletal symptoms (AIMSS) [4]. AIMSS occur in up to $54 \%$ of patients, presenting as mild or moderate joint pain, muscle stiffness, decreased grip strength, and so on [5]. AIMSS are the most common reason for postmenopausal breast cancer survivors to discontinue AI treatment $[6,7]$. Self-discontinuation of AIs because of side effects may attenuate the efficacy of AIs, thereby increasing the likelihood of cancer recurrence [8]. 
Currently, the management of AIMSS can be categorized into pharmacological and nonpharmacological therapies. Although duloxetine has a greater reduction in AIMSS, it leads to frequent adverse events, such as dry mouth, nausea, headache, and fatigue [9]. There is a lack of clinical trials that prove the safety of pharmacological therapies, so drugs cannot be widely used in clinical practice for a long period of time [10]. Yoga significantly reduced muscle aches, general pain, and physical discomfort among breast cancer survivors on hormone therapy [11]. As one of the nonpharmacological treatments, exercise programs have received much attention in recent years. An exercise program [12] refers to the prevention and improvement of AIMSS through aerobic exercise, resistance exercise, or a combination of both, and it includes activities such as yoga, walking, and swimming. Exercise intensity should be guided by an exercise trainer at a safe and comfortable pace or no more than $80 \%$ of heart rate reserve. However, the effect of exercise on AIMSS remains inconclusive. Many original studies have noted the effectiveness of exercise on AIMSS and quality of life (QOL) among breast cancer survivors taking AIs [13-15], while other researches have not reached the same conclusion [12, 16-19]. It is necessary to perform a systematic review and meta-analysis on the effect of exercise on AIMSS and QOL.

Previous systematic reviews about the effect of exercise among breast cancer survivors were conducted with searches in PubMed, the Joanna Briggs Institute (JBI), the Cochrane Library, and other electronic databases. Exercise programs could significantly improve subjective sleep problems, decrease fatigue, and control sex hormones [20-22], but none of the meta-analyses directly examined the effect of exercise on AIMSS. Thus, the current study aimed to conduct a metaanalysis on the effect of exercise on AIMSS and QOL in breast cancer survivors with AIs.

\section{Methods}

\section{Design}

This systematic review was conducted according to the guidelines of the Cochrane Collaboration [23], and the report was based on the principles of the PRISMA statement [24].

\section{Data sources and searches}

The following electronic databases were searched from their inception to May $1^{\text {st }}$, 2019: PubMed, Web of Science, EMBASE, CINAHL, Chinese Biomedical Service Platform (CBM), Wan Fang, Chinese Scientific and Technological Journal Database (VIP), and China National Knowledge Infrastructure (CNKI). Searches were restricted to studies in English and Chinese.
The main search terms used to search the databases included "breast cancer/breast neoplasms/breast tumor/breast carcinoma, exemestane/letrozole/aminoglutethimide/anastrozole/ formestane/aromatase inhibitors/aromatase inhibitor, exercise/physical activity/aerobic exercise/yoga/tai chi/walking/jogging/dance, musculoskeletal/musculoskeletal/ pain/stiffness" and so on. Free terms and keywords from the thesaurus of each database were combined. Two authors screened the studies, and they resolved disagreements via discussion or by referring to another author if necessary.

The retrieval strategy consisted of the following four steps. First, a related systematic review and meta-analysis from JBI and the Cochrane Library were conducted. Second, related original research was searched in the databases, reading the title, and abstract after removing duplicate articles by EndnoteX8 software. Third, the full text of articles that initially met the inclusion criteria was read. Last, the references of the included research studies were searched.

\section{Study selection}

Studies were eligible for inclusion if they were randomized control trials or quasi-experimental studies. Included studies examined the effectiveness of any types of exercise on AIMSS or QOL in breast cancer patients taking AIs. Two authors independently screened the studies, and they resolved disagreements via discussion or referring to the third author if necessary.

\section{Participants}

Participants had a diagnosis of breast neoplasms in accordance with diagnostic criteria [25] and were taking AIs. The severity of AIMSS was not limited. Individuals with other malignant tumors or metastatic breast cancer, and arthritis or joint pain attributed to inflammatory arthritis (such as rheumatoid arthritis, osteoarthritis, or gout) prior to hormone therapy were excluded. Those unable to exercise due to mobility issues were excluded.

\section{Intervention}

The experimental group had to exercise as defined previously. Exercise programs required specialists'guidance, although the duration, frequency, and intensity, as well as whether they were home-based or group exercise programs, were not restricted.

\section{Comparison}

Individuals in the control group were told to continue their usual activities, or they received convention care. They were not given exercise instruction until the end of the study. 


\section{Outcomes}

The included studies had to measure at least one of the outcomes: subgroup scores for AIMSS or the total QOL score. Subgroup scores of AIMSS consisted of three types of symptoms: pain, stiffness, and grip strength. All the outcomes were measured with continuous data. The score of AIMSS was measured using the BPI scale, WOMAC scale, VAS scale, electronic algometer, and so on. The QOL score was measured by self-reported measurements, including the FACT scale and SF36 scale.

\section{Quality assessment}

The quality assessment was conducted by two authors independently. The Cochrane Handbook for Systematic Reviews of Interventions Version 5.3.0 of the Cochrane Collaboration [26] was used to assess the risk of bias in the included studies and included random sequence generation (selection bias), allocation concealment (selection bias), blinding of participants and personnel (performance bias), blinding of outcome assessment (detection bias), incomplete outcome data (attrition bias), selective reporting (reporting bias), and other bias. The results of the assessment were classified as low risk, unclear risk, or high risk. The authors resolved disagreements by discussion and, if necessary, by referring to another author.

\section{Data extraction}

After reading the full text of the eligible studies, the following characteristics and outcome data were extracted by two authors: author, publication year, country/area where the study was performed, study design, sample size and mean age range, intervention of experimental and control groups, intervention details, follow-up, and the mean and standard deviation of outcomes (the score of AIMSS, including pain, stiffness, and grip strength, and the QOL score). If standard deviations were not reported in the original studies, the confidence interval (CI) and $P$ value provided were converted into standard deviation according to the method described in the Cochrane Handbook.

\section{Statistical analysis}

Data were pooled for statistical meta-analysis via RevMan 5.3 provided by the Cochrane Collaboration. All the outcomes were continuous data and expressed as a $95 \%$ confidence interval (CI) with a significance level of $\alpha=0.05$. The mean
Fig. 1 Flow chart diagram of trial identification and selection

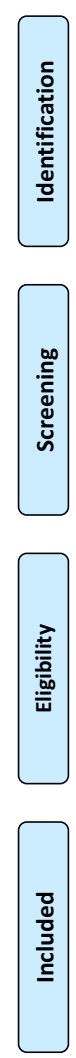

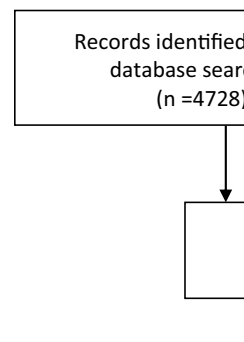
$(\mathrm{n}=2390)$
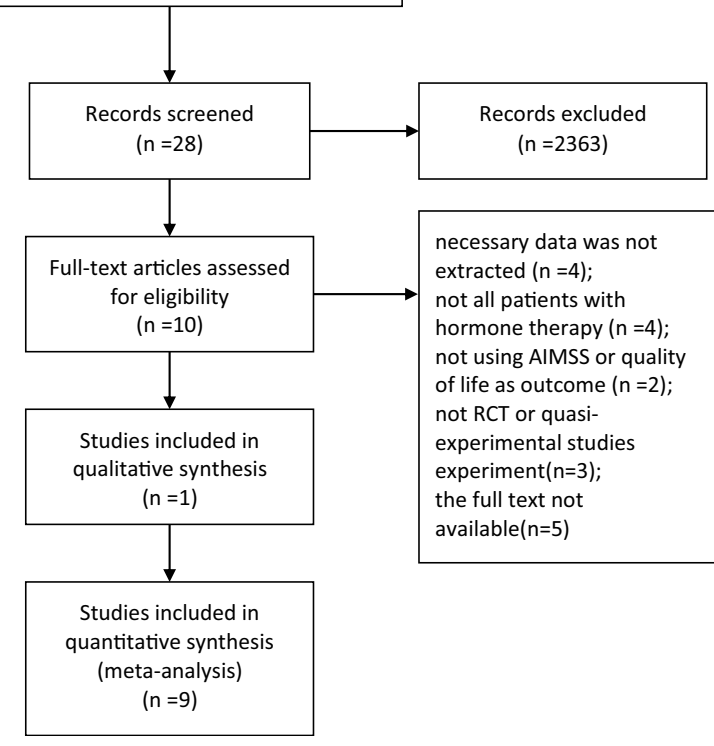

necessary data was not extracted $(n=4)$; not all patients with hormone therapy $(n=4)$; not using AIMSS or quality of life as outcome $(n=2)$; not RCT or quasiexperimental studies experiment $(n=3)$; the full text not available $(n=5)$ dditional records identified through other sources $(n=1)$

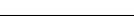




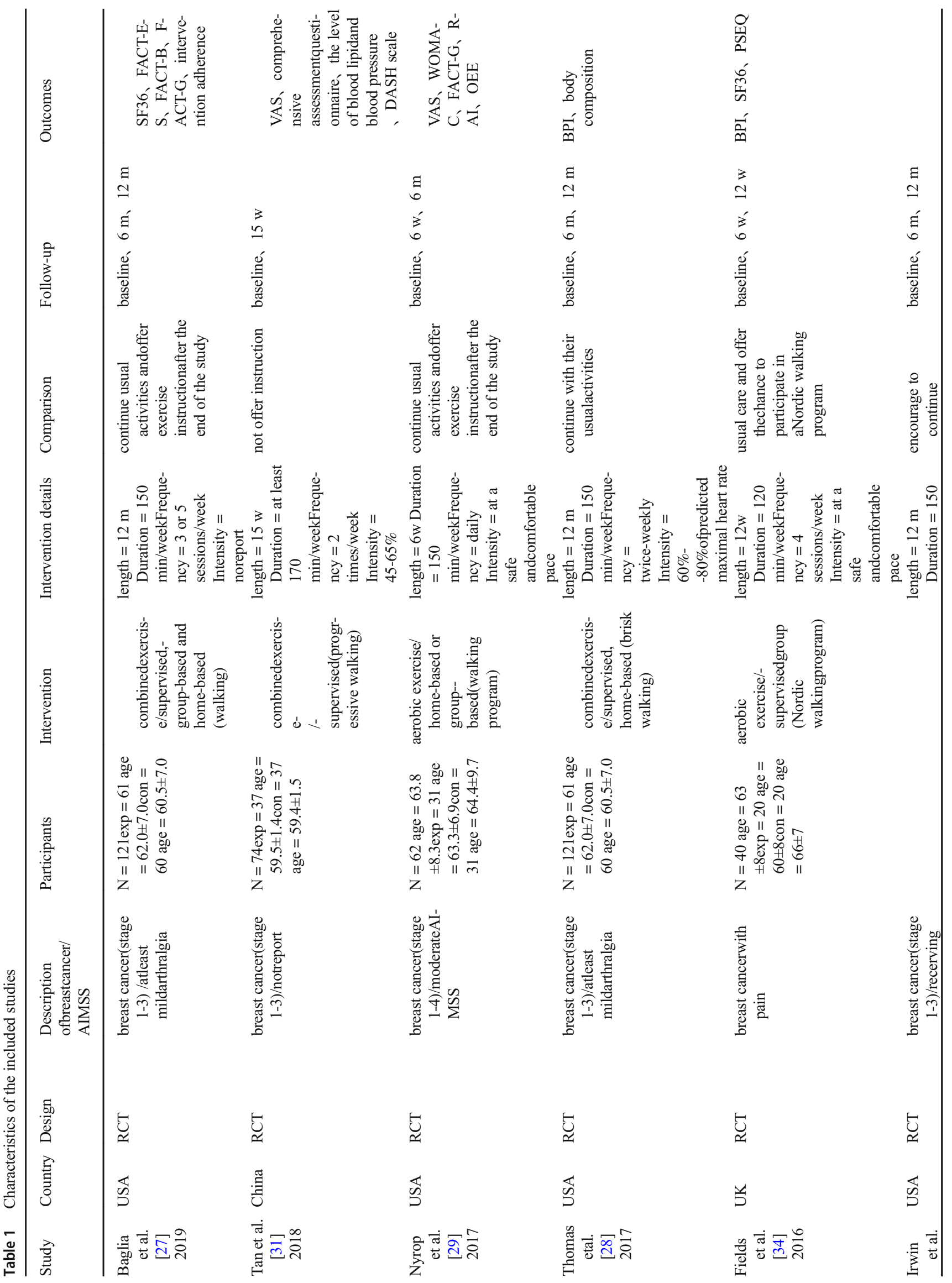




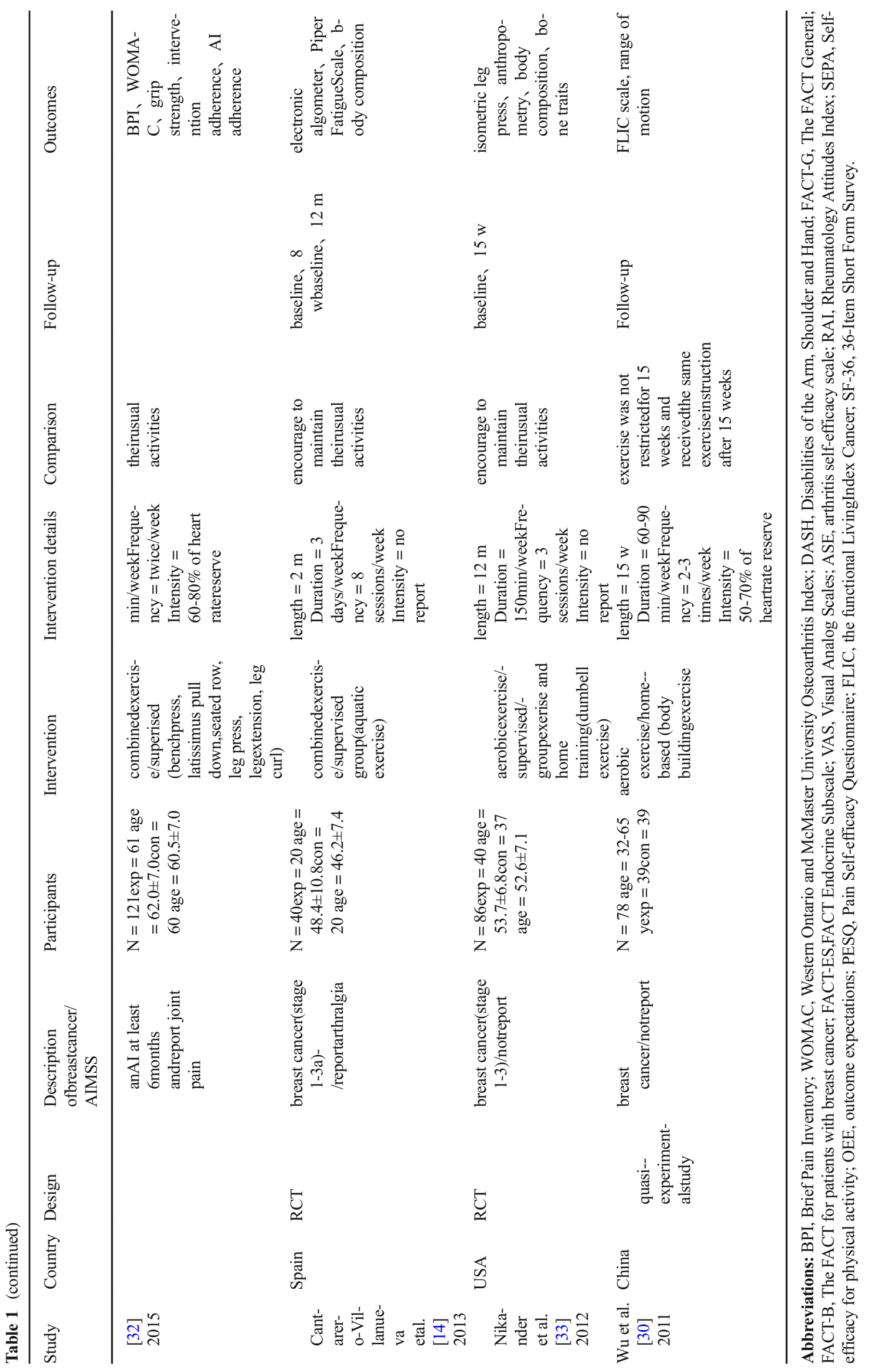


Fig. 2 Overall risk of bias assessment using the Cochrane tool

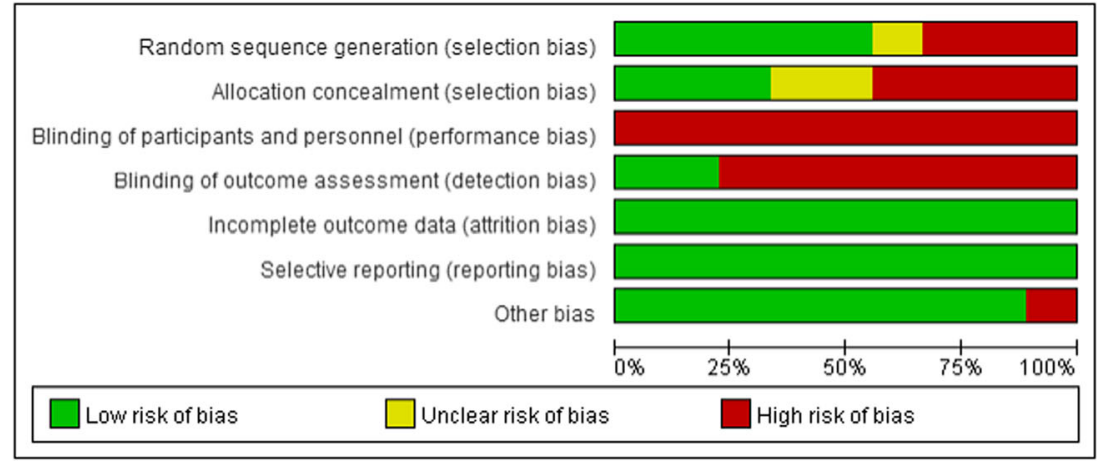

difference (MD) was calculated as an effect measure when the pooled studies used the same scale, and the standardized mean difference (SMD) was calculated when the pooled studies used different rating scales to assess outcomes. Statistical heterogeneity was tested by chi-square and $\mathrm{I}^{2}$. Random-effects models were used when $P<0.10$ and $\mathrm{I}^{2}>50 \%$. Fixed-effects models were used when $P>0.10$ and $\mathrm{I}^{2}<50 \%$. If there was a significant clinical heterogeneity between studies, descriptive

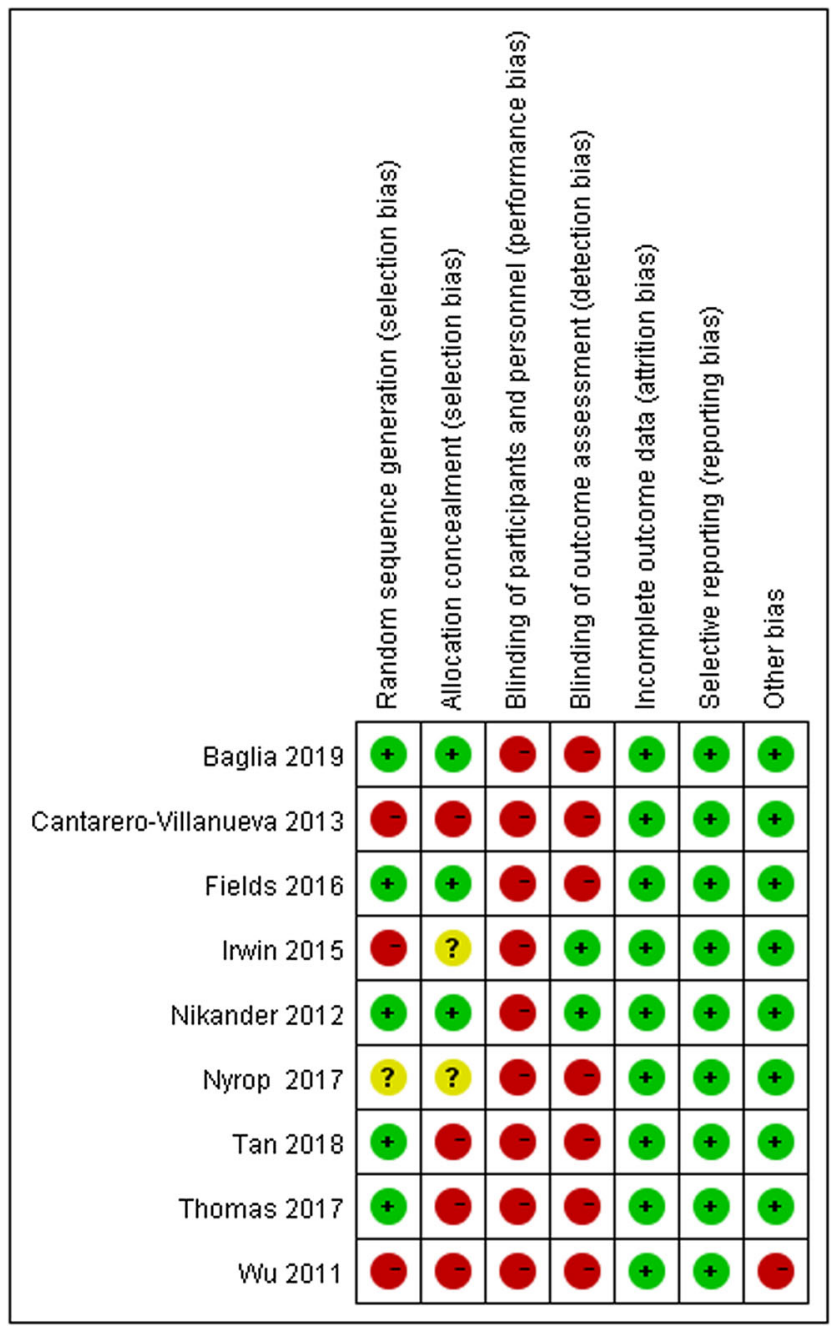

Fig. 3 Risk of bias assessment by individual trials analysis was performed. Sensitivity analysis was used to test the stability of the results.

\section{Results}

\section{Literature search}

There were nine studies included in the meta-analysis. A total of 4728 studies were retrieved from databases, and 2390 studies remained after removing the duplications via EndnoteX8 software. After reading the title and abstract, 2263 studies were excluded. After reviewing the full text of the remaining 27 articles, 8 publications were eligible for inclusion in this study [14, 27-32, 34]. One further study [33] was found through the references of the eligible publications. The retrieval process is shown in Fig. 1.

\section{Characterization of the included studies}

In the present analysis, 9 studies ( 8 RCTs and 1 quasiexperimental study) with a total of 743 participants were included. The studies were performed in the USA [27-29, 33], Spain [14], England [34], and China [30, 31]. The number of participants ranged from 40 to 121 and the mean age of the participants varied between 32 and 72 years old. The types of interventions included walking, aquatic exercise, strength training, bench press, leg press, seated row, and so on.

Aerobic exercise was performed in all studies, five of which included resistance exercise [14, 27, 28, 31, 32]. The duration of the interventions ranged from six weeks to 12 months, with at least $120 \mathrm{mins} /$ week of exercise prescribed. Training intensity varied among studies ranging from 60 to $80 \%$ of predicted maximal heart rate. There were no major adverse effects reported in the included studies. Nikander et al. [33] reported joint and muscle pain as well as stiffness because of overuse. All these symptoms were relieved after 1-2 weeks, and participants finished the exercise program. Further details about the included studies are shown in Table 1. 


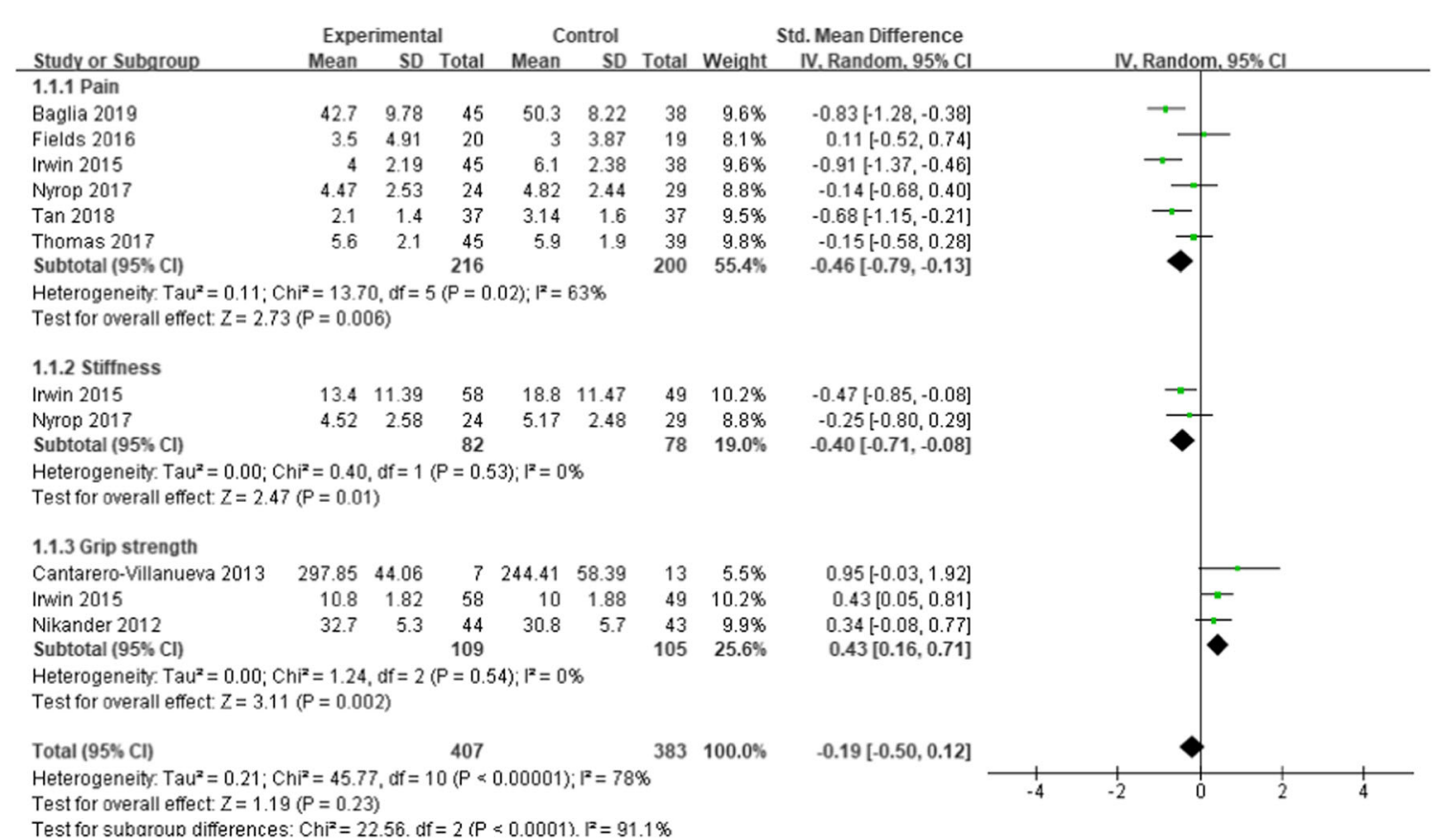

Fig. 4 The effect of exercise on changes of AIMSS in breast cancer survivors

\section{Quality of methodology of the included studies}

Five studies provided specific information on how the random sequence was generated [27, 28, 31, 33, 34]. Three provided sufficient information on allocation concealment [27, 33, 34]. Because the nature of the intervention precluded blinding patients and personnel administering the intervention, all studies were considered to be at high risk of bias. All included studies reported the data on all outcomes measured, so the selective outcome reporting bias was regarded as low risk of bias. The results are shown in Fig. 2 and 3.

\section{Effects of exercise on the total and subgroup scores of AIMSS}

Eight of the included studies measured the total score of AIMSS. In view of the different scales used in the study, SMD was used as the effect measure. The results showed that the effect of exercise on the management of AIMSS was significant.

To reduce clinical heterogeneity, subgroup analysis was conducted for different symptoms: subgroup 1 was the comparison of pain, subgroup 2 was the comparison of stiffness, and subgroup 3 was the comparison of grip strength. Six studies [27-29, 31, 32, 34] evaluated the subgroup score for pain, two studies $[29,32]$ measured the subgroup score for stiffness, and three studies $[14,32,33]$ measured the subgroup score for grip strength. The results revealed a statistically significant effect in favor of exercise on the management of pain [SMD $=-0.46,95 \%$ CI -0.79 to $-0.13, P=0.006$ ], stiffness [SMD $=-0.40,95 \% \mathrm{CI}-$ 0.71 to $-0.08, P=0.01]$, and grip strength $[\mathrm{SMD}=0.43,95 \% \mathrm{CI}$ 0.16 to $0.17, P=0.002]$, with statistical heterogeneity of 63,0 , and $0 \%$, respectively. Only when the study of Irwin et al.[32]was omitted from the analysis in the subgroup of grip strength did the results would not show a significant effect [SMD $=0.48,95 \% \mathrm{CI}$ $(-0.02,0.97), P=0.06]$ (see Fig. 4 for further details).

\section{Effects of exercise on the total QOL score}

Four of the included studies [27, 29-31] measured the QOL score. The results showed that exercise had a favorable effect on $\mathrm{QOL}$ [SMD $=2.24,95 \%$ CI 0.28 to $4.21, P=0.03$ ]. The results changed when we omitted the study of Tan et al. [31] $[\mathrm{SMD}=1.12,95 \% \mathrm{CI}(-0.07,2.32), P=0.07]$, Baglia et al. [27] [SMD $=2.74,95 \% \mathrm{CI}(-0.30,5.77), P=0.08]$, and $\mathrm{Wu}$

\begin{tabular}{|c|c|c|c|c|c|c|c|c|c|c|c|c|}
\hline \multirow[b]{2}{*}{ Study or Subgroup } & \multicolumn{3}{|c|}{ Experimental } & \multicolumn{2}{|c|}{ Control } & \multicolumn{4}{|c|}{ Std. Mean Difference } & \multirow{2}{*}{\multicolumn{2}{|c|}{ IV. Random, $95 \% \mathrm{Cl}$}} & \\
\hline & Mean & SD & Total & Mean & SD & Total & Weight & IV, Random, $95 \% \mathrm{Cl}$ & & & & \\
\hline Baglia 2019 & 174.3 & 16.81 & 45 & 158.9 & 19.96 & 38 & $25.4 \%$ & $0.83[0.38,1.28]$ & & & & \\
\hline Nyrop 2017 & 79.9 & 14.36 & 24 & 81.02 & 15 & 29 & $25.3 \%$ & $-0.07[-0.62,0.47]$ & & & & \\
\hline Tan 2018 & 33.32 & 1.15 & 37 & 27.52 & 1.21 & 37 & $24.4 \%$ & $4.86[3.94,5.79]$ & & & $\rightarrow$ & \\
\hline Wu 2011 & 78.16 & 1.37 & 39 & 69.9 & 3.03 & 39 & $24.9 \%$ & $3.48[2.76,4.19]$ & & & $\rightarrow$ & \\
\hline Total $(95 \% \mathrm{Cl})$ & & & 145 & & & 143 & $100.0 \%$ & $2.24[0.28,4.21]$ & & & & \\
\hline $\begin{array}{l}\text { Heterogeneity: Tau } \\
\text { Test for overall effec }\end{array}$ & $\begin{array}{l}3.90 ; \mathrm{Cl} \\
\mathrm{Z}=2.24\end{array}$ & $\begin{array}{l}n i^{2}=120 \\
(P=0.0\end{array}$ & $\begin{array}{l}0.89, d f \\
03)\end{array}$ & $=3(\mathrm{P}$ & $<0.0000$ & $01) ;\left.\right|^{2}=$ & $98 \%$ & & $\frac{1}{-10}$ & -5 & 5 & 10 \\
\hline
\end{tabular}

Fig. 5 The effect of exercise on quality of life in breast cancer survivors 
et al. [30] [SMD $=1.83,95 \% \mathrm{CI}(-0.39,4.06), P=0.11]$ in the QOL analysis (see Fig. 5 for further details).

\section{Discussion}

The current meta-analysis aimed to evaluate the effect of exercise on AIMSS and QOL. Regarding the blinding of participants, all studies were considered to be at high risk for performance bias because it is easy for participants to be aware of exercise. Blinding of the assessments was not possible because the primary outcome questionnaire was selfreported, except for grip strength. All studies compared baseline characteristics, such as age, education, and disease status, between the experimental group and the control group, and these characteristics were comparable. The outcomes were AIMSS and QOL, and the measurement tools varied.

The results of the meta-analysis indicate that exercise is a beneficial therapy that has a favorable effect on the management of AIMSS, in the areas of pain, stiffness, and grip strength, and on QOL in breast cancer patients taking AIs. The results were consistent with the results of previously published meta-analyses. Qiu et al. and Mishra et al. [35, 36] found that exercise was an effective intervention to improve quality of life in breast cancer survivors. Li et al. [37] concluded that strength training exercises could improve muscle strength. The current meta-analysis was comprehensive and included different interventions, both single exercises and combined exercises. Additionally, this study included participants who were postmenopausal women diagnosed with hormone-receptor-positive breast cancer, a group with a high incidence of AIMSS. To ensure patient safety, exercise was recommended under professional guidance. In the subgroup analysis, exercise was associated with a significant reduction in pain and stiffness and an improvement in grip strength. Similar results have been published. Strasser et al. [38] found that resistance exercise had positive effects on muscular function and body composition in cancer patients.

Various theoretical models have been proposed to explain the possible positive effects of exercise on breast cancer survivors taking aromatase inhibitors, although the variety of exercise types and different outcome measurement tools have lacked uniformity. Estrogen depletion has been suggested to be related to AIMSS [39]. Estrogen has attenuated pain via opioid neurons in the spinal cord; hence abruptly lowering the level of the estrogen would render patients taking AIs more sensitive to pain [40]. Exercise might play a role in increasingly releasing anti-inflammatory cytokines, while inflammation triggers hyperalgesia [41]. Kida et al. [42] have found that exercise program accelerates the circulation of body fluid to tissues and increases both skeletal muscle volume, which renders activities of daily living easier to perform and therefore less painful [43]. In addition to this, exercise may improve pain threshold via gradually increasing the range of motion and skeletal muscle strength in patients with musculoskeletal symptoms $[44,45]$. As a nonpharmacological treatment method, exercise is low intensity, convenient, and easy to accept and maintain for a long time by patients [46].

Our study has several limitations. The meta-analysis only searched studies published in Chinese and English, which may have resulted in an incomplete literature review. Additionally, statistical heterogeneity of results exists when pooling data. Sensitivity analysis was applied to detect potential sources of heterogeneity, which may have attributed to the variability in intervention models, duration, outcome measurements, and results of the exacted time point. To achieve strong consensus regarding the effect of exercise and avoid the observed heterogeneity, further clinical trials should be conducted in a more uniform manner. Lastly, it was quite difficult to identify the best exercise program based on the data in this meta-analysis. Therefore, the results of this review need to be interpreted cautiously. Comparing the effect of different interventions deserves further research to support practitioners in clinical decision-making. This is in accordance with a study reported by Buffart et al. [47], who stated that more personalized exercise programs geared toward specific health outcomes are needed to ensure the efficacy and efficiency of intervention.

\section{Conclusion}

Exercise is a safe and effective way to improve musculoskeletal symptoms and QOL in breast cancer survivors undergoing treatment with AIs. In the future, it is necessary to determine whether one type of exercise is better than another for maximum effect on AIMSS and quality of life in breast cancer patients. In addition, there is a need for more research to understand how to maintain the positive effect of exercise after the exercise intervention is completed.

\section{Compliance with ethical standards}

Conflicts of interest The authors declare that they have no conflict(s) of interest.

Statement of informed consent For this type of study, formal consent is not required.

Open Access This article is licensed under a Creative Commons Attribution 4.0 International License, which permits use, sharing, adaptation, distribution and reproduction in any medium or format, as long as you give appropriate credit to the original author(s) and the source, provide a link to the Creative Commons licence, and indicate if changes were made. The images or other third party material in this article are included in the article's Creative Commons licence, unless indicated otherwise in a credit line to the material. If material is not included in the article's 
Creative Commons licence and your intended use is not permitted by statutory regulation or exceeds the permitted use, you will need to obtain permission directly from the copyright holder. To view a copy of this licence, visit http://creativecommons.org/licenses/by/4.0/.

\section{References}

1. Cronin KA, Lake AJ, Scott S, Sherman RL, Noone AM, Howlader $\mathrm{N}$ et al (2018) Annual report to the nation on the status of cancer, part I: National cancer statistics. Cancer. 124(13):2785-2800. https://doi.org/10.1002/cncr.31551

2. Beatson GT (1896) On the treatment of inoperable cases of carcinoma of the mamma: suggestions for a new method of treatment, with illustrative cases. Trans Medico-Chirurgical Soc Edinburgh 0.15:153-179

3. Freedman OC, Fletcher GG, Gandhi S, Mates M, Dent SF, Trudeau ME, Eisen A (2015) Adjuvant endocrine therapy for early breast cancer: a systematic review of the evidence for the 2014 cancer care Ontario systemic therapy guideline. Curr Oncol (Toronto, Ont) 22(Suppl 1):S95-s113. https://doi.org/10.3747/co.22.2326

4. Honma N, Makita M, Saji S, Mikami T, Ogata H, Horii R, Akiyama F, Iwase T, Ohno S (2019) Characteristics of adverse events of endocrine therapies among older patients with breast cancer. Support Care Cancer 27:3813-3822. https://doi.org/10.1007/ s00520-019-04674-8

5. Singer O, Cigler T, Moore AB, Levine AB, Hentel K, Belfi L, Do HT, Mandl LA (2012) Defining the aromatase inhibitor musculoskeletal syndrome: a prospective study. Arthritis Care Res 64(12): 1910-1918. https://doi.org/10.1002/acr.21756

6. Henry NL, Azzouz F, Desta Z, Li L, Nguyen AT, Lemler S, Hayden J, Tarpinian K, Yakim E, Flockhart DA, Stearns V, Hayes DF, Storniolo AM (2012) Predictors of aromatase inhibitor discontinuation as a result of treatment-emergent symptoms in early-stage breast cancer. J Clin Oncol 30(9):936-942. https://doi.org/10. 1200/jco.2011.38.0261

7. Lombard JM, Zdenkowski N, Wells K, Beckmore C, Reaby L, Forbes JF, Chirgwin J (2016) Aromatase inhibitor induced musculoskeletal syndrome: a significant problem with limited treatment options. Support Care Cancer 24(5):2139-2146. https://doi.org/10. 1007/s00520-015-3001-5

8. Pineda-Moncusi M, Servitja S, Tusquets I, Diez-Perez A, Rial A, Cos ML, Campodarve I, Rodriguez-Morera J, Garcia-Giralt N, Nogues X (2019) Assessment of early therapy discontinuation and health-related quality of life in breast cancer patients treated with aromatase inhibitors: B-ABLE cohort study. Breast Cancer Res Treat 177:53-60. https://doi.org/10.1007/s10549-019-05289-7

9. Henry NL, Unger JM, Schott AF, Fehrenbacher L, Flynn PJ, Prow DM, Sharer CW, Burton GV, Kuzma CS, Moseley A, Lew DL, Fisch MJ, Moinpour CM, Hershman DL, Wade JL 3rd (2018) Randomized, multicenter, placebo-controlled clinical trial of duloxetine versus placebo for aromatase inhibitor-associated arthralgias in early-stage breast cancer: SWOG S1202. J Clin Oncol 36(4):326-332. https://doi.org/10.1200/JCO.2017.74.6651

10. Nan PENG, Xiaomin WANG (2014) Aromatase inhibitors related joint symptoms treatment status. Chin J Interg Trad West Med 34(1):109-112. https://doi.org/10.7661/cjim.2014.01.0109

11. Peppone LJ, Janelsins MC, Kamen C, Mohile SG, Sprod LK, Gewandter JS, Kirshner JJ, Gaur R, Ruzich J, Esparaz BT, Mustian KM (2015) The effect of YOCAS@® yoga for musculoskeletal symptoms among breast cancer survivors on hormonal therapy. Breast Cancer Res Treat 150(3):597-604. https://doi.org/ 10.1007/s10549-015-3351-1
12. Bevers TB, Anderson BO, Bonaccio E, Buys S, Daly MB, Dempsey PJ, Farrar WB, Fleming I, Garber JE, Harris RE, Heerdt AS, Helvie M, Huff JG, Khakpour N, Khan SA, Krontiras H, Lyman G, Rafferty E, Shaw S, Smith ML, Tsangaris TN, Williams C, Yankeelov T (2009) NCCN clinical practice guidelines in oncology: breast cancer screening and diagnosis. J Nat Compr Cancer Netw 7(10):1060-1096. https://doi.org/10.6004/jncen. 2009.0070

13. DeNysschen CA, Burton H, Ademuyiwa F, Levine E, Tetewsky S, O'Connor T (2014) Exercise intervention in breast cancer patients with aromatase inhibitor-associated arthralgia: a pilot study. Eur J Cancer Care (Engl) 23(4):493-501. https://doi.org/10.1111/ecc. 12155

14. Cantarero-Villanueva I, Fernandez-Lao C, Caro-Moran E, Morillas-Ruiz J, Galiano-Castillo N, Diaz-Rodriguez L, ArroyoMorales M (2013) Aquatic exercise in a chest-high pool for hormone therapy-induced arthralgia in breast cancer survivors: a pragmatic controlled trial. Clin Rehabil 27(2):123-132. https://doi.org/ 10.1177/0269215512448256

15. Jacobsen PB, Muchnick S, Marcus S, Amheiser P, Reiersen P, Gonzalez B, Gomez M, Jim HS, Thompson LM, Minton S, Bower J (2015) Pilot study of Iyengar yoga for management of aromatase inhibitor-associated arthralgia in women with breast cancer. Psycho-oncology 24(11):1578-1580. https://doi.org/10.1002/ pon. 3756

16. Lohrisch CA, McKenzie D, Truong P, Jesperson D, Gelmon KA, Premji S, Kennecke HF (2011) A randomized trial of exercise versus control for musculoskeletal symptoms from adjuvant anastrozole (A) for postmenopausal early breast cancer (PEBC). J Clin Oncol 29(15_suppl):636-636. https://doi.org/10.1200/jco. 2011.29.15 suppl.636

17. Fields J (2015) A feasibility study of a Nordic walking intervention for women experiencing aromatase inhibitor associated arthralgia (Doctoral dissertation, University of Southampton).

18. Nyrop KA, Muss HB, Hackney B, Cleveland R, Altpeter M, Callahan LF (2014) Feasibility and promise of a 6-week program to encourage physical activity and reduce joint symptoms among elderly breast cancer survivors on aromatase inhibitor therapy. $\mathrm{J}$ Geriatr Oncol 5(2):148-155. https://doi.org/10.1016/j.jgo.2013. 12.002

19. Galantino ML, Callens ML, Cardena GJ, Piela NL, Mao JJ (2013) Tai chi for well-being of breast cancer survivors with aromatase inhibitor-associated arthralgias: a feasibility study. Altern Ther Health Med 19(6):38-44

20. van Vulpen JK, Peeters PH, Velthuis MJ, van der Wall E, May AM (2016) Effects of physical exercise during adjuvant breast cancer treatment on physical and psychosocial dimensions of cancerrelated fatigue: a meta-analysis. Maturitas 85:104-111. https://doi. org/10.1016/j.maturitas.2015.12.007

21. Juvet LK, Thune I, Elvsaas IKO, Fors EA, Lundgren S, Bertheussen G, Leivseth G, Oldervoll LM (2017) The effect of exercise on fatigue and physical functioning in breast cancer patients during and after treatment and at 6 months follow-up: a metaanalysis. Breast (Edinburgh, Scotland) 33:166-177. https://doi.org/ 10.1016/j.breast.2017.04.003

22. Ennour-Idrissi K, Maunsell E, Diorio C (2015) Effect of physical activity on sex hormones in women: a systematic review and metaanalysis of randomized controlled trials. Breast Cancer Res 17(1): 139. https://doi.org/10.1186/s13058-015-0647-3

23. Higgins J P (2008) Cochrane handbook for systematic reviews of interventions version 5.0. 1. The Cochrane Collaboration. http:// www.cochrane-handbook.org.

24. Moher D, Liberati A, Tetzlaff J, Altman DG (2009) Preferred reporting items for systematic reviews and meta-analyses: the PRISMA statement. Ann Intern Med 151(4):264-269. https://doi. org/10.7326/0003-4819-151-4-200908180-00135 
25. Gradishar W, Salerno KE (2016) NCCN guidelines update: breast cancer. J Nat Compr Cancer Netw 14(5 Suppl):641-644

26. Higgins JP \& Green S (eds) (2011) Cochrane handbook for systematic reviews of interventions (Vol 4.) John Wiley \& Sons

27. Baglia ML, Lin IH, Cartmel B, Sanft T, Ligibel J, Hershman DL, Harrigan M, Ferrucci LM, Li F-Y, Irwin ML (2019) Endocrinerelated quality of life in a randomized trial of exercise on aromatase inhibitor-induced arthralgias in breast cancer survivors. Cancer. https://doi.org/10.1002/cncr.32051

28. Thomas GA, Cartmel B, Harrigan M, Fiellin M, Capozza S, Zhou Y, Ercolano E, Gross CP, Hershman D, Ligibel J, Schmitz K, Li FY, Sanft T, Irwin ML (2017) The effect of exercise on body composition and bone mineral density in breast cancer survivors taking aromatase inhibitors. Obesity (Silver Spring, Md) 25(2):346-351. https://doi.org/10.1002/oby.21729

29. Nyrop KA, Callahan LF, Cleveland RJ, Arbeeva LL, Hackney BS, Muss HB (2017) Randomized controlled trial of a home-based walking program to reduce moderate to severe aromatase inhibitor-associated arthralgia in breast cancer survivors. Oncologist 22(10):1238-1248. https://doi.org/10.1634/ theoncologist.2017-0174

30. QingShi W, Kuanru L, Runyao L, Baoling Y (2011) Influence of self-developed aerobic exercise on life quality of breast cancer patients. J Nurs China 7. https://doi.org/10.3969/j.issn.1008-9969. 2011.07.004

31. Yanfang T, Jie L, Fangping Z (2018) Effect of combined exercise on blood lipids in postmenopausal hormone receptor-positive breast patients. China Modern Med 25(33):50-52

32. Irwin ML, Cartmel B, Gross CP, Ercolano E, Li F, Yao X, Fiellin M, Capozza S, Rothbard M, Zhou Y, Harrigan M, Sanft T, Schmitz K, Neogi T, Hershman D, Ligibel J (2015) Randomized exercise trial of aromatase inhibitor-induced arthralgia in breast cancer survivors. J Clin Oncol 33(10):1104-1111. https://doi.org/10.1200/jco.2014. 57.1547

33. Nikander R, Sievanen H, Ojala K, Kellokumpu-Lehtinen PL, Palva T, Blomqvist C, Luoto R, Saarto T (2012) Effect of exercise on bone structural traits, physical performance and body composition in breast cancer patients - A 12-month RCT. J Musculoskelet Neuronal Interact 12(3):127-135

34. Fields J, Richardson A, Hopkinson J, Fenlon D (2016) Nordic walking as an exercise intervention to reduce pain in women with aromatase inhibitor-associated arthralgia: a feasibility study. J Pain Symptom Manag 52(4):548-559. https://doi.org/10.1016/j. jpainsymman.2016.03.010

35. Jiajia Q, Ping L (2017) Effectiveness of aerobic exercise on quality of life in breast cancer survivors: a meta-analysis. Chin J Nurs 52(03):300-306. https://doi.org/10.3761/j.issn.0254-1769.2017. 03.010

36. Mishra SI, Scherer RW, Snyder C, Geigle PM, Berlanstein DR, Topaloglu O (2012) Exercise interventions on health-related quality of life for people with cancer during active treatment. Clin Otolaryngol 37(5):390-392. https://doi.org/10.1111/coa.12015
37. Cheng L, Aifeng M, Fang C, Xiaoxu Z, Shizheng DU, Ping ZHU, LiFang YANG, Mengting PAN, Fang H (2018) A systematic review on effect of resistance exercise on upper limb lymphedema and muscle strength in postoperative breast cancer patients. J Nurs Sci 33(9):97-101. https://doi.org/10.3870/j.issn.1001-4152.2018. 09.097

38. Strasser B, Steindorf K, Wiskemann J, Ulrich CM (2013) Impact of resistance training in cancer survivors: a meta-analysis. Med Sci Sports Exerc 45(11):2080-2090. https://doi.org/10.1249/MSS. 0b013e31829a3b63

39. Ho SC, Chan SG, Yip YB, Cheng A, Yi Q, Chan C (1999) Menopausal symptoms and symptom clustering in Chinese women. Maturitas 33(3):219-227

40. Dawson-Basoa M, Gintzler AR (1998) Gestational and ovarian sex steroid antinociception: synergy between spinal kappa and delta opioid systems. Brain Res 794(1):61-67

41. Petersen AMW, Pedersen BK (2005) The anti-inflammatory effect of exercise. J Appl Physiol 98(4):1154-1162

42. Kida K, Osada N, Akashi YJ, Sekizuka H, Omiya K, Miyake F (2008) The exercise training effects of skeletal muscle strength and muscle volume to improve functional capacity in patients with myocardial infarction. Int J Cardiol 129(2):180-186. https://doi. org/10.1016/j.ijcard.2008.04.031

43. Church TS, Earnest CP, Skinner JS, Blair SN (2007) Effects of different doses of physical activity on cardiorespiratory fitness among sedentary, overweight or obese postmenopausal women with elevated blood pressure: a randomized controlled trial. JAMA 297(19):2081-2091

44. Schmitz KH, Ahmed RL, Troxel A, Cheville A, Smith R, LewisGrant L, Bryan CJ, Williams-Smith CT, Greene QP (2009) Weight lifting in women with breast-cancer-related lymphedema. N Engl J Med 361(7):664-673. https://doi.org/10.1056/NEJMoa0810118

45. Jones MD, Booth J, Taylor JL, Barry BK (2014) Aerobic training increases pain tolerance in healthy individuals. Med Sci Sports Exerc 46(8):1640-1647. https://doi.org/10.1249/MSS. 0000000000000273 .

46. Arem H, Sorkin M, Cartmel B, Fiellin M, Capozza S, Harrigan M, Ercolano E, Zhou Y, Sanft T, Gross C, Schmitz K, Neogi T, Hershman D, Ligibel J, Irwin ML (2016) Exercise adherence in a randomized trial of exercise on aromatase inhibitor arthralgias in breast cancer survivors: the hormones and physical exercise (HOPE) study. J Cancer Survivorship 10(4):654-662. https://doi. org/10.1007/s11764-015-0511-6

47. Buffart LM, Galvao DA, Brug J, Chinapaw MJ, Newton RU (2014) Evidence-based physical activity guidelines for cancer survivors: current guidelines, knowledge gaps and future research directions. Cancer Treat Rev 40(2):327-340. https://doi.org/10.1016/j.ctrv. 2013.06.007

Publisher's note Springer Nature remains neutral with regard to jurisdictional claims in published maps and institutional affiliations. 